\title{
Search Engine Art: Internet Imperialism and the image in context
}

\author{
Gretchen Andrew \\ Los Angeles, California \\ USA \\ gretchenandr@gmail.com
}

\begin{abstract}
Compare the image search results for "boy crawling" and "girl crawling." In the first you see cute babies, in the second you see scantily clad women in seductive poses. Similarly compare "boy at work" with "girl at work" or "school boy" with "school girl." This sexist representation of women is a result of Google's extremely profitable revenue model. Conduct an image search (images.google.com) for "Amazon." Do the same for "Cherokee." The results, dominated by the ecommerce company and the car brand respectively, tell us something important about how the internet works and who is more likely to benefit: companies over communities and products over people. Not only is the current Internet unequal but artificial intelligence is programmatically encoding this discrimination into our future. Artificial intelligence uses large data set, such as all the images of "girls" on the internet, and learns to label future images based on common characteristics found in the initial data set. Machines are learning that girls are sexualized women while they are learning that boys are young male children. We don't know the full impact of Al, but it is already being built into technology we trust and depend on. It may not equally respect us all. Internet Imperialism is Search Engine Artist Gretchen Andrew's method of intentionally structuring information dominate the online definition or reputation of a place or idea. It is a central part of her art practice through which she manipulates search results, swapping existing image results for her paintings. In doing so, she creates a less product-focused Internet that encourages discussion about how the internet could better come to reflect the human complexity we see IRL (in real life). This paper discusses these topics and shares examples of past \& ongoing artworks including sharing of the artist's method of Internet Imperialism.
\end{abstract}

Search Engine Art. Internet Imperialism. Education of Artificially Intelligent Machines. Structural Bias.

\section{INTRODUCTION}

In 1929, when René Magritte wrote "This is not a pipe" under his painting of a pipe, he was playing with the relationship between an object and its representation. Today, search is how text becomes image, how sign becomes symbol, how words become flesh. It is how meaning and definition are established.

Image search in particular sits at the intersection of representation and meaning. When we enter text into the search bar and receive images as results it may appear that endless deferral of meaning, as described by poststructuralism, ends. However, a basic understanding of how image search operations exposes dependence on the same unreliable words. This obscures that the inherent problems of language have actually been exacerbated.
Now that the internet, through the lens of search engines and the optimization algorithms they operate with, is the arbiter of definition interesting things are happening. Whatever a pipe is or is not, Google determines it.

\section{HOW SEARCH ENGINES WORK}

In the beginning the internet was a canvas of potential but difficult to navigate. Search engines, like Google with its $87 \%$ global market share, learned to crawl like spiders over web pages, helping us find what we were looking for, helping what was looking for us do the same.

Because of Google's global market dominance this research is focused on Google but many of the points are true for other common search engines such as Bing and Blekko. 
Google returns search results ranked by a complex series of dynamic signals including time, date, location, metadata, alt text, readability of site, and how many popular sites link to the results.

Companies buy ads that display within Google search result but also spend time and money conducting Search Engine Optimization, SEO. SEO involves designing web pages and online content in a way that increases visibility within search engines. Companies hope to get a return on their investments through increased sales of their products and services.

\subsection{Implication: companies over communities, products over people}

Conduct an image search (image.google.com) for "Amazon" and for "Cherokee." The results, dominated by the e-retailer and car respectively, tell us something essential about the structure of the internet and who is more likely to benefit: products over people and companies over communities.

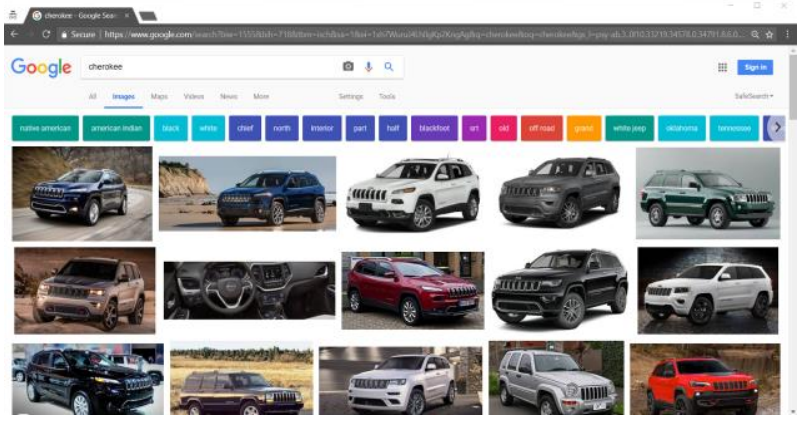

This is because companies, unlike communities, spend the time and money speaking to search engines. They are economically incentivised to do so.

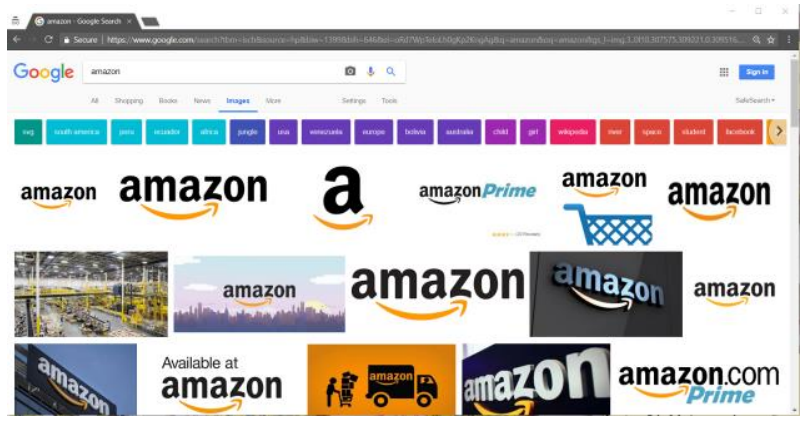

Figure 2: Image search results for "Amazon"

\subsection{Implication: sexism}

Because the female body has a history of being productised it, like the Cherokee or Amazon, will always surface within search results as a product before as a person.

Table 1: Google profits from the productisation and related sexualisation of the female body

\begin{tabular}{|l|l|}
\hline \multicolumn{1}{|c|}{$\begin{array}{c}\text { Search } \\
\text { keyword }\end{array}$} & \multicolumn{1}{|c|}{$\begin{array}{c}\text { Price Google Charges } \\
\text { Per Click }\end{array}$} \\
\cline { 2 - 2 } & Prices (January 2018) \\
\hline BOY & $\$ 0.23$ \\
\hline GIRL & $\$ 0.43$ \\
\hline
\end{tabular}

Figure 1: Image Search Results for "Cherokee"

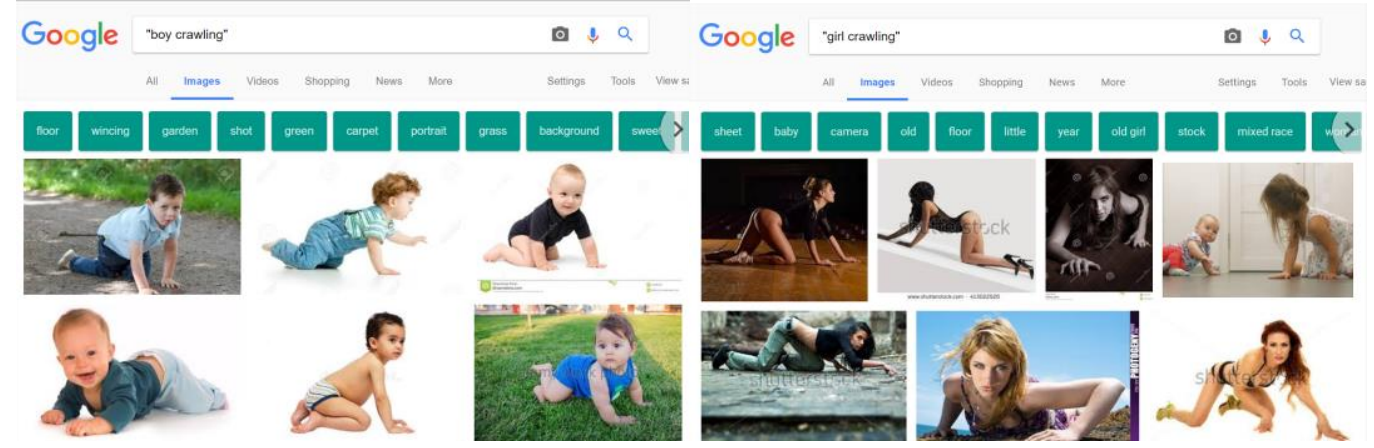

Figure 3: Compare how males and females are represented online (Andrew 2018b)

\subsection{Implication: language \& artificial intelligence}

Google is working with a type of artificial intelligence known as Deep Neural Nets (Andrew 2017). If you feed enough photos of a platypus into a neural net, it can learn to identify a platypus.
But it is one thing when you are discussing a word for which a definition is binary, something that either is or is not a platypus.

However, consider:

- Man vs woman?

- House vs shack vs mansion? 
When conducting an image search, where does Google:

- Stop returning yellow and start returning orange?

- Stop defining as black and start saying white?

- Draw the line between rich and poor?

Very few definitions exist without nuance, without what post-structuralists call "slippage" between definitions. Al exacerbated problems that are inherent within language. With $\mathrm{Al}$, any holes that exist in language get automated into how the world is defined. Moreover, a service like image search obscures its initial dependence on language those making it harder to understand how certain words turn into certain images.

\section{INTERNET IMPERIALISM}

Internet Imperialism is my method of intentionally structuring of information to dominate the online definition or reputation of a place or idea. It is a central part of my art practice through which I manipulate search results, swapping existing image results for my paintings. Definitions are highly manipulatable if you know how to structure information.

But the point is not just to prove that the internet's authority can be easily manipulated but also to actively make the internet a more creative place where artificially intelligent machines get educated from the present of art.

As I stated in my Wikimedia RFC Manifesto (Andrew 2018a):

"Art constitutes a unique form of knowledge that often conveys its information through the productive introduction of uncertainty instead of the firming of facts. When we look at a painting one of the important and often unconscious transmissions that occurs is that the way the world is seen and understood is subject to personal interpretation. Through art we receive a jarring and expanding awareness of otherness. Through art we can make machines less sure that they have a complete handle on what it means, and looks like, to be human. Art can do the same thing for us humans."

\subsection{Method}

Internet Imperialism is a form a search engine art where I intentionally structure websites, XML, HTML and meta information to dominate the online definition or reputation of a place or idea. In doing so I manipulate search results, swapping existing results for my paintings and drawings. By dominating search results with my drawings my work questions where the internet's authority comes from and how its image culture could become reflective of the diversity and complexity found IRL ("in real life"). Key elements include:

- Alt text

- Image size

- Anchor text

- Linked set of content sites

- Custom URL

- XML sitemaps

- Image file name

\subsection{Examples}

\subsection{1 "Malignant Epithelial Ovarian Cancer"}

I was able to manipulate these search results to be dominated by my paintings through a creative structuring of information including metadata, HTML and XML. Before I applied my method of Internet Imperialism as Search Engine Art, the results for ovarian cancer were very clinical, having nothing to do with the experience, which for me is marked by my family relationships and a fear of my own body. By "hacking" the search results to be of my paintings, instead of medical diagrams, I hope to expand the definition and serve as a reminder that all images, including diagrams and photographs, have bias and perspective. My hope is that paintings within this context provoke questions of how search engines work and how they can and are used for more sinister manipulations.

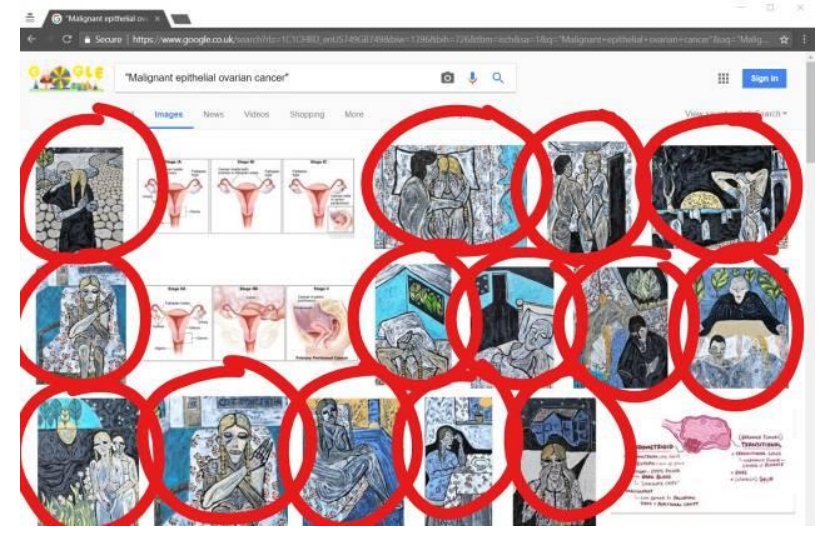

Figure 4: Screenshot of image search results for "Malignant epithelial ovarian cancer" where my paintings are circled in red

\subsection{2 "Bow New Hampshire"}

This is a screenshot of image search results for "Bow New Hampshire" where my paintings circled are red. I was able to manipulate these search results to be dominated by my paintings through a creative structuring of information including metadata, HTML and XML. I call this process Internet Imperialism: the intentional structuring of information to dominate the online definition or 
reputation of a place or idea. It is a central part of my art practice through which I manipulate search results, swapping existing image results for my paintings. In doing so I share how much truth is manipulatable if you just know how to structure information. My hope is that paintings within this context lead to discussions about the internet as a tenuous form of authority

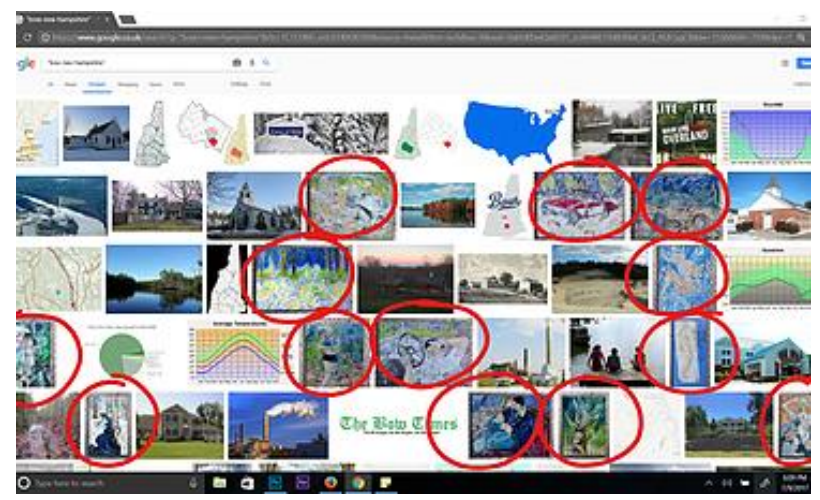

Figure 4: Screenshot of image search results for "Bow New Hampshire" where my paintings are circled in red

\subsection{2 "Billy Childish Paintings"}

These are paintings I completed, copying my mentor Billy Childish. Traditionally this is known as making an "after" painting, but this Search Engine Art demonstrates the internet's inability to handle nuance. We can't really say that the internet is wrong to return Billy Childish paintings made by Gretchen Andrew along with Billy Childish
Paintings made by Billy Childish. We as humans can easily understand what it means for a painting to be an "after" but the internet lacks the ability to make this distinction.

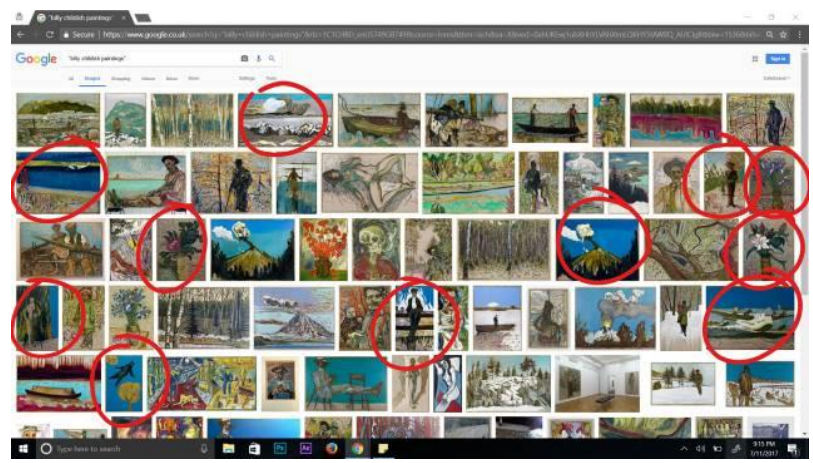

Figure 5: Screenshot of image search results for "Billy Childish Painting" where my paintings are circled in red

\section{REFERENCES}

Andrew, G. (2017) Implications of Al. Art, Architecture and $\mathrm{Al}$, Cambridge University, March.

Andrew, G. (2018a) Art and the Education of Intelligent Machines. Wikimedia Commons RFC.

Andrew, G. (2018b) Google Makes the Internet Sexist. (To appear.) 